\title{
Study on Prevalence and Distribution of Salmonella Isolates from Apparently Healthy Sheep and Goats Slaughtered at Addis Ababa Abattoir Enterprise, Ethiopia.
}

\author{
Bedaso Kebede Kassaye ${ }^{1 *}$, Dinsefa Jemal Hassen ${ }^{1}$, Kifle Alemu Leja $^{2}$ and Biniam Tsegaye ${ }^{2}$ \\ ${ }^{1}$ Veterinary Drug and Animal Feed Administration and Control Authority, Ministry of Agriculture, Addis Ababa, Ethiopia \\ ${ }^{2}$ Haramaya University, College of Veterinary Medicine, Haramaya, Ethiopia
}

"Corresponding author: Bedaso Kebede Kassaye, Veterinary Drug and Animal Feed Administration and Control Authority, Ministry of Agriculture, Addis Ababa, Ethiopia, Tel: +251913136824; E-mail: ebede.bedaso@yahoo.com

Rec date: Sep 07, 2015; Acc date: Oct 14, 2015; Pub date: Oct 16, 2015

Copyright: (c) 2015 Kassaye BK, et al. This is an open-access article distributed under the terms of the Creative Commons Attribution License, which permits unrestricted use, distribution, and reproduction in any medium, provided the original author and source are credited.

\begin{abstract}
A cross-sectional study was carried out from November 2010-April 2011 to determine the prevalence and distribution of salmonella isolates from apparently healthy sheep and goats slaughtered at Addis Ababa Abattoir enterprise, Addis Ababa, Ethiopia. A total of 384 sheep and goats were randomly selected and examined for the presence of salmonella in liver, kidney, spleen, carcass, mesenteric lymph node and feces. Three hundred eighty four samples of liver $(0.00 \%)$, kidney $(0.00 \%)$, spleen $(0.00 \%)$, muscle $(0.00 \%)$, carcass $(0.00 \%)$, mesenteric lymph node $(1.9 \%)$ and feces $(5.3 \%)$ were examined. The isolation and identification of salmonella were carried out according to the technique recommended by the Standard Technique. Out of 384 samples, a total of $4(1.04 \%)$ salmonella were isolated of which $1.5 \%(n=200)$ and $0.5 \%(n=184)$ were from sheep and goats respectively. Out of the positive isolates, $2(2.6 \%)$ and $1(3.6 \%)$ were from faeces and mesenteric lymph node of sheep and $1(3.7 \%)$ was from feces of goats. The result revealed that there was no statistically significant difference $(p>0.05)$ in the prevalence of salmonella between male $(1.14 \%)$ and female $(1.79 \%)$ sheep and male $(100 \%)$ and female $(0.00 \%)$ goats. There was also no statistical significant difference between adult $(1.96 \%)$ and young $(1.02 \%)$ sheep and also between adult $(100 \%)$, and young $(0.00 \%)$ goats. The prevalence of salmonella in sheep $(1.5 \%)$ and in goat $(0.54 \%)$ was not significantly associated $(p>0.005)$. Finally, the result of present study shows that unhygienic practices of workers resulted in contamination of mesenteric lymph node and the possibilities of cross contamination between positive animal and healthy ones. Although the present study shows the low prevalence of salmonella in the study area, the important impacts of salmonellosis on sheep and goats' production and productivity should not be neglected. Therefore, emphasis should be given to control the disease.
\end{abstract}

Keywords: Prevalence; Salmonella; Sheep; Goats

\section{Introduction}

Sheep and goats are the most numerous domestic livestock that are especially important in the extreme climates of the world. Small ruminants in Africa are noted for their ability to convent low opportunity cost feed into high value products, namely; meat, milk, fiber, manure and hides [1,2]. Tropical Africa has high population of small ruminants but productivity is generally low with low contribution to the total gross domestic production (GDP) [3].

Ethiopia has an extremely diverse topography, a wide range of climatic features and a multitude of agro-ecological zones which makes the country sustainable for different agricultural production systems and this intern has contributed to the existence of the diversity of farm animal's genetic resources in the country. In spite of the presence of a huge small ruminant population, Ethiopia fails to optimally exploit these resources. This has been determined due to number of technical and non-technical factors including ill-health, poor production, infrastructure and inadequate managerial knowledge of the owners health disorders in all classes of small ruminants represents the major problems that greatly affect the economy of sheep and goats production [4]. Ethiopia has a huge livestock potential including a total of 24 million sheep and 18 million goats distributed in different geographical areas of the country. Taking into accounts off take and growth rate, the country has the capacity to put into market 2.1 million sheep and 5 million goats live per year. Considering the domestic consumption, it has been reported that there is a reliable source to supply sheep and goat meat of 7,000 and 16,200 tons respectively for export market annually [5]. In spite of high demands from imports, the country has been supplying less amount of livestock and livestock products not because of lack of resource but due to certain infrastructural defects such as small numbers of standard export abattoir as compared to huge livestock number, uncontrolled expansion of illegal trading of livestock, presence of various zoonotic and epidemic disease as well as food borne illness [5].

Among the food borne illness an incident in which two or more individuals experienced a similar illness after ingestion of a common food and an epidemiologic analysis implicated the food as the source of illness for salmonellosis [6]. It is an economically important disease of all animal's species including sheep and goats where infection of animals with various species of salmonella can result in serious clinical disease and always constitute a host reservoir of infection for humans [7]. Salmonella infections are an important cause of morbidity and mortality, thus remained an important problem both in industrialized and developing countries of the world. Although the incidence varies across countries, it is one of the most wide spread food borne zoonoses [8]. 
Salmonellosis is caused by many species of salmonella where the genus salmonella is a typical member of the family Enterobacteriaceae characterized by Gram negative, straight sided, rod shaped bacteria, where most of the species are motile by peritrichous flagella [9]. The disease is characterized by one or more of three major syndromes: septicemia, acute enteritis and choric enteritis. Although their resulting clinical patterns are not distinct, different species of salmonellae tend to differ in their epidemiology [10]. The epidemiologic pattern differ greatly between geographic areas depending on climate, population density, land use farming practices, food harvesting and processing technologies and consumer habits [11]. Animals are the hosts and the principal vectors of zoonotic salmonellosis. The prominent epidemiological factor is the common carrier status in animals. The absences of symptoms in the majority of infected animals and the technical difficulties in detecting such carrier before or during meat inspection make them a continuing source of contamination of the environment and hence of animal products [11]. Salmonella have a wide variety of domestic animal and wild animal hosts. The disease in the meat animals including sheep and goats arises from intensive rearing practices, use of contaminated feed and water, and cross contamination of carcass during slaughtering operations, stress associated with prolonged deprivation of feed and water, transport of animals from rearing farm to abattoir crowding and prolonged lairage in abattoir, pens, parturition and administration of certain drug predispose animal to infection $[7,12]$.

The infection in a given host may or may not be clinically apparent in subclinical form, the animal may have a latent infection but harbor the pathogen in its lymph node or it may be a carries and eliminate the agent in its fecal material briefly, intermittently or persistently [13]. In the clinical form of the disease, animals may exhibit septicemia, acute enteritis or chronic enteritis. The septicemic form usually has a syndrome in lambs and kids characterized by depression and marked fever $\left(40.5-41.5^{\circ} \mathrm{c}\right)$ which may end in death in $48 \mathrm{hrs}$ [10]. In acute enteric form which is the most common in adults, fever and severe watery diarrhea or dysentery, with pungent smell mucus feces is typical. Mild fever, soft feces, in appetence and high incidence of abortion in ewes and high mortality due to enteritis in lamb is the characteristic of the sub-acute enteritis. The chronic enteritis is manifested by persistent diarrhea, emaciation and poor response to treatment $[7,10]$. Clinical salmonellosis can be diagnosed based on clinical sign and laboratory examination of the feces, tissue from affected animals, feed and water [10]. However, identification of carrier animal is the most difficult clinicopathological problem as such animals may shed bacteria intermittently and it may be necessary to examine specimens taken from them on number of occasions before positive culture is obtained. It needs standard cultural methods for isolation of salmonella which may take up to five days for presumptive identification of the bacteria [14]. The method include sequential culturing which involves Pre-enrichment (resuscitation), enrichment, plating out and different biochemical and serological test according to the set standards [15]. The most important route of transference of salmonella organism from animal to man is via animal food products meat, milk and eggs, which may be contaminated at a source and cause infection in man [8]. The prevention of out breaks of this type of human food poisoning constitute a world problem which emphasizes the responsibility of the veterinarian to control and prevent animal salmonellosis not only from economic and human point of view but also an essential task in reducing the incidence of similar human infections [16]. Contamination of red meat by salmonella organism may occur at the abattoir from symptomless animals' execrators, contaminated abattoir equipment and floor where the salmonella gain access to meat at any stage during slaughtering operation [17]. The persistence of salmonella in the porcine, bovine and ovine meat industries may also originate from the exposure of livestock to environmental sources of contaminated feeds and from parental transmission of infection [8]. Despite the difficulties to properly evaluate the situation of the disease in developing countries, there is still lack of epidemiological surveillance system and limited scope of studies in Ethiopia [13]. Certain studies carried out on poultry meat, cattle, minced meat and humans in Ethiopia has showed that salmonella are quite prevalent in various food animals, animal product and human being [18-21]. Although no more study has so far been carried out to determine the salmonella carrier rate of sheep and goats in Ethiopia, studies carried out elsewhere confirmed that small ruminant have a significant role in food borne infection due to salmonella $[11,17,22,23]$. As salmonellosis is primarily an enteric infection and feces are often responsible for contamination of other carcass in unhygienic abattoir, an examination of fecal sample is necessary and also on its courses to spread to other parts of the body, the salmonella may be trapped in mesenteric lymph node, spleen, liver, kidney, abdominal muscle, feces and carcass [24].

Therefore, these organ need to be assed to determine the carrier rate of salmonella and the presented study was carried out to determine the prevalence and distribution of salmonella in sheep and goats slaughtered at Addis Ababa abattoir enterprise.

\section{Materials and Methods}

\section{Study area}

The study was conducted from November 2010 to March 2011 at Addis Ababa Abattoir enterprise located in central part of Ethiopia at latitude about $90030 \mathrm{~N}$ and longitude of about $380420 \mathrm{E}$ and at an elevation ranging from 2000-2800 meters above sea level. The study area receives a mean annual rainfall of about $1089 \mathrm{~mm}$ which comes from the long and short rainy seasons and the mean annual minimum and maximum Temperature is $15.920^{\circ} \mathrm{C}\left(60.50^{\circ} \mathrm{F}\right)$ and $250^{\circ} \mathrm{C}\left(77.00^{\circ} \mathrm{F}\right)$ respectively. The abattoir supply meat and its edible organ to the consumer in Addis Ababa. Daily the abattoir slaughters about 80 to 150 cattle and annually the abattoirs slaughters from 28800 to 54750 cattle with a few number of meat inspectors assigned by ministry of Agriculture.

\section{Study animals, design and sample size determination}

The study animals were apparently healthy sheep and goats slaughtered at Addis Ababa abattoir enterprise. Animals of both sexes which were brought from different parts of country were tried to be included in the study. In this study, animals were grouped in to young (under 1 year of age in goats and lyears and 3 months in sheep) based on eruption of one or more incisor teeth according to Gatenby [25] and Steele [26]. A cross-sectional study was undertaken to determine the prevalence and distribution of salmonella in liver, kidney, spleen, mesenteric lymph node, muscle (abdominal and diaphragmatic), carcass, and feces [24]. Sample size determination was performed according to the methods previously provided by Thrushfied [27]. The following formula was used to calculate the number of animals to be sampled. 
Citation: Kassaye BK, Hassen DJ, Leja KA, Tsegaye B (2015) Study on Prevalence and Distribution of Salmonella Isolates from Apparently Healthy Sheep and Goats Slaughtered at Addis Ababa Abattoir Enterprise, Ethiopia. . J Veterinar Sci Technol 6: 268. doi: 10.4172/2157-7579.1000268

Page 3 of 5

$$
\mathrm{N}=\frac{1.96^{2}[\mathrm{Pexp}(1-\text { pexp })]}{D^{2}}
$$

Where $\mathrm{N}$ is the required sample size, Pexp was the expected prevalence and $\mathrm{D}$ is the desired absolute precision. Since there were no previous researches done on the study site, an expected prevalence of $50 \%$ was taken to give a total of 384 animals by considering a $5 \%$ absolute precision and at $95 \%$ confidence level. The sample units were selected using simple random sampling method from those animals brought for slaughtering.

\section{Study Methodology}

Sample collection: All samples were collected aseptically from sheep and goats during slaughtering operation. All samples; feces, carcass, liver, spleen, kidney, mesenteric lymph node, and muscles (abdominal and diaphragmatic muscle), were collected aseptically using sterile cotton swab for organ samples and put into sterile universal bottles with peptone water for transportation and enrichment media [24]. All samples were labeled legibly indentifying species of the animal, age, sex and type of sample and sampling ID number. After putting the samples in an ice box with ice pack, they were brought immediately to the microbiology laboratory of Shola zonal veterinary laboratory for bacteriological processing.

Culture procedure: The method used for the culture of salmonella was according to the technique recommended by the International Organization for Standardization (Quinn et al. 1994 and ISO, 2002). The Swab sample was taken and inoculated into pre-enrichment medium (BPW) and incubated for 16 to $20 \mathrm{hrs}$ at $370^{\circ} \mathrm{C}$. Then plating out on selective medium in petridishes (Maconkey agar to differentiate non lactose fermentation) $24 \mathrm{hrs}$ at $37^{\circ} \mathrm{C}$. Then inoculated in first medium (Brilliant green agar) and second medium xylose lysine dexoychlorate (XLD) incubated at $37^{\circ} \mathrm{C}$ for $20-24 \mathrm{hrs}$. Then the colony was characterized from cultured medium and incubated on nutrient agar at $370^{\circ} \mathrm{C}$ for $18-24 \mathrm{hrs}$. Finally, different biochemical test for interpretation of the result was performed.

Plating out and identification: A loop full of enrichment broth was on to pre-incubated maconkey agar, after $24 \mathrm{hr}$, non-lactose fermenter then sub culture on to pre-incubated brilliant green-phenol red lactose-sucrose agar (BPLS) and xylose lysine deoxychlorate (XLD) prepared on a large sized petridishes $(90 \mathrm{~mm})$ and incubated at $37 \mathrm{for}$ $24 \mathrm{hrs}$. The plates were then examined for the presence of typical salmonella colonies. On BPLS, salmonella appear red surrounded by bright red zone and the culture medium become red too. Super imposed on the red colonies is the production of $\mathrm{H} 2 \mathrm{~S}$ so most salmonella have red colonies is with a black center in xylose lysine deoxychlorate (XLD) medium. This could likely be salmonella, which was subjected to successive biochemical tests after culturing pure colonies on nutrient agar.

Biochemical Test: Those colonies cultured on nutrient agar were subjected to the following biochemical tests. TSI, Urase, Simon's citrate agar, Indole, typical biochemical reaction, that means alkaline slant (red), acid butt(yellow) and $\mathrm{H} 2 \mathrm{~S}$ production on TSI,citrate utilization, Urase negative and Indole negative indicate presumptive positive reaction to salmonella.

Data Analysis: The Data were entered into Microsoft excel spread sheets and was analyzed using STATA (version 11) statistical software package. Descriptive statistics was used to determine the prevalence of salmonellosis in the study area. The association of infection with the different factors was analyzed using $\mathrm{x}^{2}$ test. A statistically significant association between variables is considered to exist if the calculated pvalue is less than 0.05 with $95 \%$ confidence level.

\section{Results}

\section{Prevalence result}

In the present study, a total of 384 samples were taken of which 200 and 184 were from sheep and goats respectively. The samples were examined for the presence of salmonella, of which $4(1.04 \%)$ were positive for salmonella. Out of the four positive samples, $3(1.5 \%)$ were obtained from sheep and $1(0.54 \%)$ from goats (Table 1$)$. Despite the increase in the number of positive samples for salmonella in adult sheep (1.96\%) as compared to young (1.02\%), there was no significant statistical association $\left(\mathrm{P}=0.584, \mathrm{x}^{2}=0.299\right)$. while there was only one positive sample from goats which was positive for salmonella (Table 2). Even though there was an increase in the number of positive samples for salmonella in the ewe $2(1.79 \%)$ as compared to the ram $1(1.14 \%)$, there was no significant statistical association $\left(\mathrm{p}=0.708, \mathrm{x}^{2}=0.1406\right)$ and one buck $1(100 \%)$ which was positive for salmonella (Table 3 ). There was an increase in the prevalence of salmonellosis in sheep $3(1.5 \%, \mathrm{n}=200)$ as compared to goats $1(0.54 \%, \mathrm{n}=184)$. However, there were no statistical association between the two species $(\mathrm{P}=0.356$, $\left.\mathrm{x}^{2}=0.8506\right)$ (Table 4$)$.

\begin{tabular}{|c|c|c|c|c|c|c|}
\hline \multirow[b]{3}{*}{$\begin{array}{l}\text { Type of } \\
\text { samples }\end{array}$} & \multicolumn{6}{|c|}{ Number of samples } \\
\hline & \multicolumn{2}{|l|}{ Sheep } & \multicolumn{2}{|l|}{ Goats } & \multicolumn{2}{|l|}{ Total } \\
\hline & Examined & (\%) & $\begin{array}{l}\text { Examine } \\
\text { d }\end{array}$ & $(\%)$ & $\begin{array}{l}\text { Examine } \\
\text { d }\end{array}$ & (\%) \\
\hline Liver & 28 & $0(0)$ & 26 & $0(0)$ & 54 & 0 \\
\hline Kidney & 30 & $0(0)$ & 26 & $0(0)$ & 56 & 0 \\
\hline Spleen & 28 & $0(0)$ & 26 & $0(0)$ & 54 & 0 \\
\hline Muscle & 28 & $0(0)$ & 27 & $(0)$ & 55 & 0 \\
\hline $\begin{array}{l}\text { Mesenteric } \\
\text { lymph node }\end{array}$ & 28 & $1(3.6)$ & 26 & $0(0)$ & 54 & $1(1.9)$ \\
\hline Carcass & 28 & $0(0)$ & 26 & $0(0)$ & 54 & 0 \\
\hline Fecal & 30 & $2(6.7)$ & 27 & $1(3.7)$ & 57 & $3(5.3)$ \\
\hline Total & 200 & $3(1.5)$ & 184 & $1(0.54)$ & 384 & $4(1.04)$ \\
\hline
\end{tabular}

Table 1: Prevalence of salmonella on sample type and species of animals.

\begin{tabular}{|l|l|l|l|l|l|l|}
\hline \multicolumn{2}{|l|}{$\begin{array}{l}\text { Species } \\
\text { Examined }\end{array}$} & Adult & Young & Total & X2 & $\begin{array}{l}\text { P. } \\
\text { value }\end{array}$ \\
\hline \multirow{3}{*}{ Sheep } & Negative & $100(98.04 \%)$ & $97(98.98 \%)$ & $197(98.50 \%)$ & & \\
\cline { 2 - 7 } & Positive & $2(1.96 \%)$ & $1(1.02)$ & $3(1.50 \%)$ & 0.299 & 0.584 \\
\cline { 2 - 7 } & Total & $102(100 \%)$ & $98(100 \%)$ & $200(100 \%)$ & & \\
\hline \multirow{2}{*}{ Goats } & Negative & $93(50.82 \%)$ & $90(49.18 \%)$ & $183(100 \%)$ & & \\
\cline { 2 - 7 } & Positive & $1(100 \%)$ & $0(0.00 \%)$ & $1(100 \%)$ & 0.963 & 0.327 \\
\hline
\end{tabular}


Citation: Kassaye BK, Hassen DJ, Leja KA, Tsegaye B (2015) Study on Prevalence and Distribution of Salmonella Isolates from Apparently Healthy Sheep and Goats Slaughtered at Addis Ababa Abattoir Enterprise, Ethiopia. . J Veterinar Sci Technol 6: 268. doi: $10.4172 / 2157-7579.1000268$

Page 4 of 5

\begin{tabular}{|l|l|l|l|} 
Total & $94(51.09 \%)$ & $90(48.91 \%)$ & $184(100 \%)$
\end{tabular}

Table 2: Prevalence of salmonella in different age groups of sheep and goats.

\begin{tabular}{|l|l|l|l|l|l|l|}
\hline \multicolumn{2}{|l|}{$\begin{array}{l}\text { Species } \\
\text { Examined }\end{array}$} & Adult & Young & Total & $\mathbf{x}^{2}$ & $\begin{array}{l}\text { P. } \\
\text { value }\end{array}$ \\
\hline \multirow{3}{*}{ Sheep } & Negative & $87(98.86 \%)$ & $110(98.21 \%)$ & $197(98.5 \%)$ & & \\
\cline { 2 - 7 } & Positive & $1(1.14 \%)$ & $2(1.79 \%)$ & $3(1.50 \%)$ & 0.1406 & 0.708 \\
\cline { 2 - 7 } & Total & $88(100 \%)$ & $112(100 \%)$ & $200(100 \%)$ & & \\
\hline \multirow{2}{*}{ Goats } & Negative & $79(43.17 \%)$ & $104(56.83 \%)$ & $183(100 \%)$ & & \\
\cline { 2 - 7 } & Positive & $1(100 \%)$ & $0(0.00 \%)$ & $1(100 \%)$ & 1.3071 & 0.253 \\
\cline { 2 - 7 } & Total & $80(43.48 \%)$ & $104(56.52 \%)$ & $184(100 \%)$ & & \\
\hline
\end{tabular}

Table 3: Prevalence of salmonella in different sex of sheep and goats.

\begin{tabular}{|l|l|l|l|l|l|}
\hline Species & $\begin{array}{l}\text { Number of animals } \\
\text { examined }\end{array}$ & Positive & Prevalence & $\mathbf{x}^{2}$ & P-value \\
\hline Sheep & 200 & 3 & 1.50 & 0.8506 & 0.356 \\
\hline Goats & 184 & 1 & 0.54 & & \\
\hline Total & 384 & 4 & 1.04 & & \\
\hline
\end{tabular}

Table 4: Comparison in the prevalence of salmonella infections between sheep and goats.

\section{Discussions}

In the present study the carrier state of salmonella in apparently healthy sheep and goats slaughtered at Addis Ababa abattoir enterprise was $1.5 \%$ and $0.54 \%$ respectively. There is no standard set prevalence range for salmonella in apparently healthy slaughtered sheep and goats. However, D'Aoust [8] cited few studies on the prevalence of salmonellae on sheep and goats undertaken in different parts of world ranging between 2 to $51.5 \%$ in sheep and 1 to $18.8 \%$ in goats. However, the same author reported a prevalence of $14.7 \%$ in sheep $(n=307)$ which was higher than the current finding. This might be due to the fact that animals had been held in the market for longer period before slaughtered where stress could probably had induced higher infection rate among the animals. But this did not hold true for small ruminants slaughtered at Addis Ababa Abattoir enterprise where the animals only stayed for maximum of two days before slaughtered.

Studies undertaken in Indian abattoir indicated a relatively lower prevalence in both species that means $3.1 \%$ and $3.8 \%$ in apparently healthy slaughtered sheep and goats respectively [13]. Sharma et al [28] also indicates $2.32 \%$ salmonella prevalence in goats. A relatively lower prevalence rate in our study might be due to lower salmonella carrier state in the study area population. In addition, animals that are going to be slaughtered stayed in the abattoir lairage less crowded and kept for at least lower than one week which might have decreased the transfer of infection among the animals. Certain studies have shown that there is a direct relationship between salmonella infection rate in small ruminants and cattle where an increase in the infection rates of the latter has coincided with high incidence of the same serotype in the former [25]. This may occur more likely for lairage and abattoirs where the slaughtering operation takes place in the same room. In our study, the lairage and slaughter house of small ruminants were in the different room. In addition, sheep and goats were kept in a separate area from cattle in lairage. The small ruminants were driven in the different path as compared to the cattle where there was no possible contact with the feces before slaughtering operation takes place.

The present study indicated that $6.7 \%$ and $3.7 \%$ of salmonella prevalence in the feces of sheep and goats respectively. Nabbut and AlNakhali [17] recorded a $4.7 \%$ salmonella positive fecal sample from apparently healthy sheep and goats slaughtered. Identification of salmonella in feces indicates the fecal contamination of the edible organs may present as a potential hazard. Nabbut and Al-Nakhali [17] recorded only $0.8 \%$ of the spleen of sheep $(n=280)$ to be positive for salmonella. In the present study $0.0 \%$ spleen and $6.7 \%$ feces of sheep were salmonella positive. Furthermore study conducted on apparently healthy slaughtered sheep in Australia indicated at $4 \%$ prevalence of salmonella in mesenteric lymph node [29]. These all indicates a considerable importance of sheep as a reservoir of salmonella that can precipitate food borne infection in human studies on the salmonella carrier rate where in goats also indicated a significant importance of this species in the epidemiology of salmonella. In our study the highest prevalence of salmonella was observed in feces $(3.7 \%)$ than mesenteric lymph node $(0.0 \%)$, liver $(0.0 \%)$ or spleen $(0.0 \%)$ of the examined goats, which indicates the organisms didn't extensively spread from feces.

There was no contamination of the carcass of sheep and goats with salmonella during the study period. This result was lower than the finding of Moo et al. [29] who reported an average salmonella infection rate of mutton to be $5 \%$ which was destined for export all over Australia. Furthermore, the structure of abattoir and certain slaughtering practice such as poor disinfections of knifes, and other equipment, slaughter floor drains, poor personal hygiene of slaughter house personal and poor contamination of carcass [19,30]. Studies undertaken in Ethiopia underlined that personal working in slaughter house play a significant role being a source of contamination of carcasses $[19,21]$. In our study there was an increase in the number of positive samples for salmonellae in the female $2(1.79 \%)$ as compared to the male $1(1.14 \%)$ in sheep where there was no significant statistical association. This may be due to the increase in the sample size of females. There was an increase in the number of positive samples for salmonella in adult $2(1.96 \%)$, and $1(100 \%)$ in sheep and goats respectively. This may be due to the increased adult sample size of in both species.

\section{Conclusion and Recommendations}

The present result indicated the detection of salmonella in mesenteric lymph node, which indicates lymphatic spread of organism and at the same time presence of salmonella in the feces. In this study salmonella were isolated from slaughtered sheep and goats in both female and male animals. The result of the present study not only shows the unhygienic practices of workers, but also the carrier state of the animals which resulted in the contamination. Therefore, in order to achieve a better control of salmonella contamination during the slaughtered process, the following recommendations are forwarded:

Care must be taken to minimize cross contamination of salmonella through equipments and workers from salmonella positive slaughtered sheep and goats to healthy ones. 
Citation: Kassaye BK, Hassen DJ, Leja KA, Tsegaye B (2015) Study on Prevalence and Distribution of Salmonella Isolates from Apparently Healthy Sheep and Goats Slaughtered at Addis Ababa Abattoir Enterprise, Ethiopia. . J Veterinar Sci Technol 6: 268. doi: $10.4172 / 2157-7579.1000268$

Page 5 of 5

Appropriate meat inspection services should be practiced in the slaughterer house, so that potential zoonoses can be avoided or at least minimized.

Proper decontamination and disinfection measures should be provided at the entrance of slaughter houses to reduce cross contamination.

Training should be given to slaughter house personnels on the risk of infection during slaughtering process, means of preventing cross contamination and others.

Further researches should be undertaken in order to evaluate the potential pathogens and their source to prevent and control zoonotic infectious agents.

\section{Acknowledgment}

We are indebted of Haramaya University for financial support.

\section{References}

1. FAO (1986) Small ruminant production in the developing countries. In: proceeding of the Expert consultation held in Sofia, Bulgaria 58: 138.

2. Wilsmore $\mathrm{T}$ (2006) Diseases of small ruminants in Ethiopia. The Veterinary Epidemiology and Economics Research Unit (VEERU) school of Agriculture policy and development, The University of read, UK pp: 6-7.

3. ILCA (1999) International livestock center for Africa Annual report and ILCA. Addis Ababa lands ILCA Addis Ababa, Ethiopia P. 10.

4. Bekele M, Feseha G, Shibriu T (1995) Survey of Gastrointestinal tract helminthes in sheep slaughtered at Addis Ababa, Ethiopia. Journal of Agriculture Science. 4: 87-94.

5. LMA (Livestock marketing authorities) (1995) Prons and cons of Ethiopia live animal and meat export.

6. Petersen KE, James WO (1998) Agents, vehicles, and causal inference in bacterial foodborne disease outbreaks: 82 reports (1986-1995). J Am Vet Med Assoc 212: 1874-1881.

7. Radostitis OM, Blood DC, Gay CC, Hinchclity KW (2007) Disease caused by salmonellae species. In: veterinary medicine a text book of disease of cattle, sheep, pigs, goats and horse. (9thedn) Baillere Tindall, London P. 816

8. D'Aoust JY (1994) Salmonella and the international food trade. Int J Food Microbiol 24: 11-31.

9. Varnam AH, Evans MG (1991) Salmonellae In: food borne pathogens. An illustrated text, Wolfe publishing Ltd, Aylerbury, England pp: 51-85.

10. Carlton LD (1998) Salmonollosis In: the merk veterinary manual. (8th Edn) NJ pp:120-123.

11. World health organization (1998) Report of WHO export committee on salmonellosis control: the role of animal and product hygiene: world health organization technical report series, WHO, Geneva 774.
12. D'Aoust JY (1989) Salmonellae In: Doyle M (9th Edn) Food borne bacterial pathogens. Marcel Dekker Inc New York, pp: 328-413.

13. Acha PN, Szyfres B(2001) salmonellosis In: zoonosis and communicable disease common to man and animals.(3rdedn) Pan American health organization, Washington DC, pp: 233-246.

14. House JK, Smith BP (1998) Current strategies for managing salmonellae infection in cattle. Veterinary medicine pp: 756-764.

15. Pieskus J, Milius J, Michalskiene I, Zagrebneviene G (2006) The distribution of Salmonella serovars in chicken and humans in Lithuania. J Vet Med A Physiol Pathol Clin Med 53: 12-16.

16. Buxton A, Fraser A (1997) Salmonellae In: Animal microbiology,Black well scientific publishing Ltd, oxford pp: 103-116.

17. Nabbut NH, Al-Nakhali HM (1982) Incidence of salmonellae in lymph node, spleen and feces of sheep and goats slaughtered in Riyadh public abattoir. J food prot 45: 1314-1317.

18. Nyeeleti C, Molla B, Hildebrandt G, Kleer J (2000) The prevalence and distribution of salmonella in slaughtered cattle. Slaughtered house personnel and minced beef in Addis Abeba, Ethiopia. Bull Anim Hlth Prod Afr 48: 17-24.

19. Pegram RG, Roeder PL, Hall ML, Rowe B (1981) Salmonella in livestock and animal by-products in Ethiopia. Trop Anim Health Prod 13: 203-207.

20. Alemayehu D, Molla B, Muckle A (2003) prevalence and antimicrobial resistance pattern of salmonellae in isolates from apparently healthy slaughtered cattle in Ethiopia Trop. Anim Hlth Prod (In press).

21. Molla B, Kleer J, Sinell HJ (2003) Occurrence, distribution and level of Salmonella in selected food items in Addis Ababa, Ethiopia. Fleischwirt Int 4: 37-39.

22. Kumar S, Saxena SP, Gupta BK (1973) Carrier rate of salmonellas in sheep and goats and its public health significance. J Hyg (Lond) 71: 43-47.

23. Sojka WJ, Wray C, Shreeve J, Benson AJ (1977) Incidence of salmonella infection in animals in England and Wales 1968--1974. J Hyg (Lond) 78: 43-56.

24. Quinn PJ, Markey BK (2003) Concise review of veterinary microbiology. Back well publishing pp: 6 .

25. Gantenby RM (1991) Sheep: The tropical Agriculturist. Macmillan education Limited, London and Basingstoke pp: 1-2.

26. Steele M (1996) Goats: The tropical Agriculturist, Macmillan education Limitted, London and Basingstoke pp: 1-2.

27. Thrushfield M (2005) Veterinary Epidemiology survey. (2nd Edn) By Black well science ltd, a black well publishing company Editorial office. Pp: 183.

28. Sharma RN, Musonda MM, Munnang's HM, Muyoetal P, Sinyangwe PG (1996) salmonellae isolation from animals in the public of Zambia. Bull Anim Hlth prod Afri 44:5-7.

29. Moo D, O'Boyle D, Mathers W, Frost AJ (1980) The isolation of Salmonella from jejunal and caecal lymph nodes of slaughtered animals. Aust Vet J 56: 181-183.

30. Adesiyun AA, Oni O (1989) Antibiogram of salmonellae in slaughtered cattle. Slaughter areas and offluents in Zaria slaughter house, Nigeria. JF prot 52: 232-235. 